\title{
Setting Favourable Habitat Reference Values for breeding birds: general principles and examples for passerine birds
}

\author{
MATTIA BRAMBILLA, CLAUDIO CELADA and MARCO GUSTIN
}

\section{Summary}

Setting Favourable Reference Values (FRVs) can assist the definition of the conservation status of a species. FRVs may consider population, habitat, and range. FRVs can indicate a range of values for different parameters, which should allow the long-term persistence of a species/population. We propose a method for the definition of reference values for the habitat (FRV-H or HRV) of breeding bird species. HRV should cover habitat extent and quality, both required to ensure longterm persistence. Extent HRV should express a measure of suitable area, whereas quality HRV could be defined as the range of values for habitat variables known to affect habitat quality. To define an extent HRV, we built species distribution models (SDMs) and set extent HRV as the extent of potentially suitable habitat under a conservative approach. Quality HRV should refer to environmental determinants/correlates of occurrence and breeding success, and should be defined by the identification of the habitat factors affecting occurrence and reproduction. When habitat selection is adaptive, habitat suitability may approximate habitat quality, being correlated with breeding success. In that case, fine-scaled habitat/distribution models may be used to identify determinants/correlates of reproductive output, and such species-habitat relationships may help define quality HRV. We show examples using the Red-backed Shrike Lanius collurio as a model. The use of habitat selection models, which can be made spatially explicit generating distribution models, may assist the definition of both extension and quality HRVs. Species-habitat models can allow the individuation of factors and relative values affecting species occurrence/reproduction (quality HRV), and the definition of the spatial distribution and quantity of potentially suitable habitat (extent HRV). Our approach is one of the possible ones, aiming at finding a "suitable" trade-off between affordable data and scientific precision. HRVs should be used together with population and range FRVs to assess the status of a species/population.

\section{Introduction}

Setting favourable reference values (FRVs) can assist the definition of the conservation status of a species (Brambilla et al. 2011), together with other criteria, such as demographic and range variation, within-species genetic variability and functional characteristics of ecosystems (Mehtala and Vuorisalo 2007). The guidelines for monitoring and reporting the conservation status of species and habitats of EU interest require member States to evaluate the conservation status of species, to assess their demographic trends and to provide an FRV for each species (European Commission 2005). FRVs can indicate thresholds (or a range of values) for different parameters, which should allow the long-term persistence of a species or a population. Species with all parameters lying above the FRVs are likely to be in "good" conservation status, whereas species with one or more parameters below the respective reference values are likely to be in a bad or inadequate 
conservation status (Gustin et al. 2009, 2010). The reference values may contribute to effective conservation planning because species or populations whose parameters strongly deviate from FRVs may be considered more 'at risk', and they can allow basic and transparent assessments of conservation status. FRVs should be used to evaluate conservation status, in particular to assess whether a species can be considered in favourable conservation status (FCS) or not. FRVs can be formulated for at least three different parameters. Until now, reference values have been proposed for bird populations, but not for other potentially important parameters, such as habitat or range, although these two other parameters are also advocated in the monitoring process proposed by the European Union within the framework defined by the EU Habitats Directive ( $92 / 43 / \mathrm{CEE})$ and Wild Birds Directive (09/147/EC), which represent the main tools for EU member states to act against biodiversity decline.

According to EU guidelines, FCS for a species can be achieved only when all the following conditions are fulfilled: i) population data indicate that the species will survive in the long-term and will be a viable element within its habitat; ii) the species' range is not declining, nor at risk of decline; iii) the habitat of the species is of adequate size and will remain so to maintain its population on the long term.

FRVs (for range, habitat, population) should be established on a scientific basis, based on the best available conservation knowledge and in a transparent way. 'Best expert judgement' may be used to define it in absence of other data (European Commission 2005). Establishing FRVs must be distinguished from establishing concrete targets: setting targets is the translation of reference values into operational, practical and feasible short-, medium- and long-term targets/milestones. Member states are therefore encouraged to include FRVs in their monitoring reports, as the establishment of such values will strongly support discussions on status assessment and priority setting at the biogeographical or national level. Until now, except for a concise report on species conservation status in Denmark (Pihl et al. 2006) and population FRV in Italy (Brambilla et al. 2011), none of the member states of the EU has provided a comprehensive evaluation of FRVs for its breeding bird species included in Annex I of the Wild Birds Directive.

Following the rationale of the EU directives, we propose a practical method for the definition of reference values for the habitat of breeding bird species in Italy (FRV-H, or HRV, Habitat Reference Value). HRV should be used in a complementary way to population and range FRV for a thorough evaluation of the species/population conservation status.

\section{Methods}

\section{The Habitat Reference Value as a two-sided concept}

The HRV should span two dimensions: habitat extent, and quality. Habitat extent can be measured as the area potentially suitable for a given species, and extent HRV should be large enough to allow the population to be at its FRV or above in the long term. Habitat quality should theoretically be evaluated through fitness measures of a population (e.g. breeding success, survival, etc.). Habitat quality is "the ability of the environment to provide conditions appropriate for individual and population persistence" and varies according to resource available for survival, reproduction and population persistence (Hall et al. 1997). It is commonly measured through breeding success, as the latter is often the demographic feature most easily measured in the field.

On the basis of the above, HRV should refer to both habitat extent and habitat quality, as both are required to ensure long-term persistence of a species or population. According to the extent concept, HRV should express a measure of suitable area, whereas, in the case of quality, HRV could be theoretically defined as a base value or a range of values for some habitat variables or parameters which are known to affect habitat quality via an effect on reproduction or survival of a species. The commonest way to measure habitat quality is to evaluate the effect of habitat variables on breeding output (Förschler et al. 2005, Bionda and Brambilla 2012). 
As an alternative, one may use the factors affecting probability occurrence as a proxy of the factors affecting habitat quality, on the basis of an adaptive habitat choice displayed by species: habitat selection is an adaptive process in many species, for which the most attractive habitats are also those which allow a higher breeding success (Sergio et al. 2003, 2004, Ortego 2007, Brambilla et al. 2010a, Brambilla and Ficetola 2012). Habitat suitability/attractiveness is likely to be a rough approximation of habitat quality in those species also, but it could be the only feasible one in several cases, as for many species it is hard to collect enough data to estimate breeding success and survival and to relate them to habitat parameters. However, one should be always aware of the risk tied to the potential occurrence of ecological traps and other mismatches between selected habitats and breeding performance: considering habitat suitability as a measure of habitat quality in those species will lead to a misinterpretation of the species-habitat relationships.

\section{Extent HRV}

HRV should indicate a reference measure of the potentially suitable habitat, for a given species within a given geographical area (national, regional, etc.), and can be expressed in $\mathrm{km}^{2}$ (e.g. national scale), or in ha (regional scale). The proposed extent should be enough to support the population at or above FRV.

To define an extent HRV, we built a distribution model using machine-learning, presence-only methods. Correlative species distribution models (SDMs) define relationships between occurrence points and environmental features and evaluate the environmental suitability of a given area for a given species. Models thus provide a measure of occurrence probability, which can be used for a variety of purposes (Araújo and Williams 2000, Ferrier et al. 2002, Raxworthy et al. 2003, Graham et al. 2004, Bourg et al. 2005, Thuiller et al. 2005, VanDerWal et al. 2009, Brambilla et al. 2009, 2010b, Fouquet et al. 2010, Elith et al. 2011). In the most recent years, such models have shown growing importance, and presence-only models are becoming prevalent (JiménezValverde et al. 2008).

We used the software MaxEnt (Maximum Entropy Modelling, version 3.3.3k Phillips et al. 2006) to build SDMs relating species presence to environmental variables. MaxEnt assesses the probability of presence in a given cell on the basis of environmental features in that cell; it is considered one of the most efficient approaches to SDM using presence-only data (Elith et al. 2006, 2011).

Then we established values to set extent HRV as the extent of potentially suitable habitat under a conservative approach. The values most commonly used to define a cell as either suitable or unsuitable are the maximum training sensitivity plus specificity threshold and the equal training sensitivity and specificity threshold. Whenever the two values coincide, all areas above such thresholds should be considered suitable. When the two thresholds differ, we suggest considering as unsuitable - all areas below the lowest threshold; partly suitable - the areas with values between the two thresholds, and suitable - all areas above the highest threshold.

\section{Quality HRV}

The reference value for habitat quality should refer to environmental determinants (or at least correlates) of occurrence and breeding success of a species. Quality HRV should be defined by means of the identification of the habitat factors (e.g. landscape structure, vegetation traits, etc.) affecting species occurrence and reproductive output. However, this is not always possible and in several cases surrogates have to be used. When habitat selection is adaptive, i.e. most selected sites are also the ones which enable higher breeding outputs, habitat suitability may approximate habitat quality, being correlated with breeding success. When such an assumption is realised, finescaled habitat or distribution models may be used to identify environmental determinants or correlates of reproductive output, and species-habitat relationships defined by such models may help identify factors and respective values important for habitat quality and thus for the definition of quality HRV. The modelled relationships and the relative response curves may reveal thresholds, 
or range of values, potentially suitable to define a set of variables (and respective values), which concur to the definition of quality HRV.

We show an example with Red-backed Shrike Lanius collurio, based on SDMs realised by means of MaxEnt, and on the species-habitat relationships modelled by the program, which uses a flexible approach able to model also non-linear relationships. Model outputs may reveal the most important variables affecting species distribution (on the basis of estimates of variable importance such as jackknife test and percentage contribution) and the species response to such variables. The range of values corresponding to high probability occurrence can be selected as optimal values for the species, and thus used to define quality HRV. SDMs built using fine-scaled habitat traits related to landscape and vegetation structure, instead of rough bioclimatic data, may provide robust and detailed assessments, potentially able to estimate also breeding parameters (Brambilla and Ficetola 2012), thus qualifying as particularly suitable for the purposes of this work.

Apart from SDMs, other models quantitatively describing habitat preferences and factors affecting breeding success can similarly help define important habitat factors and relative "favourable" values (Brambilla et al. 2012a).

Given that HRVs should indicate habitat conditions "optimal" for a species, both for occurrence and reproduction, we argue that values suggested for HRV should describe optimal habitats, not just "suitable" ones.

HRV definition can hardly account for potential variation in habitat use during the course of the year, as many species breed within one habitat and then migrate or overwinter in others. Because of practical constraints, HRV for breeding bird species should primarily deal with habitat occupied during the breeding season. However, some species use different breeding habitats sequentially during a single season, and HRV definition may also concern species which can perform intra-seasonal dispersal between one brood and subsequent broods (Brambilla and Rubolini 2009, Gilroy et al. 2010, Brambilla and Pedrini 2011, Kragten 2011, Brambilla et al. 2012b). SDMs may help to evaluate both extent and quality HRVs in this problematic group of species, and species-habitat models should be produced and compared for all the main periods of the breeding season (e.g. for time of first and second brood).

\section{Study model}

We developed examples to show a practical application of our approach, by defining extent and quality HRV on the bases of SDMs. We built an SDM (using MaxEnt) for the Red-backed Shrike in Lombardy (c. $24,000 \mathrm{~km}^{2}$ ), northern Italy. The Red-backed Shrike is a passerine typically inhabiting low-intensity farming landscapes, with grasslands, shrubs and hedgerows. It needs both low vegetation plots (such as mown or grazed grassland) for feeding and shrubs and small trees for perching and nesting (Casale and Brambilla 2009). The SDM for the species was based on 863 independent territories mapped during the breeding season from 2007 and 2011 over the entire regional territory; methods and habitat variables were the same adopted by Brambilla and Ficetola (2012). The selected features for the model were linear, quadratic and hinge (Brambilla et al. 2013a). The model (Figure I) shows excellent discriminatory ability (AUC of the ROC plot equal to 0.941 ).

\section{Results}

\section{Extent $H R V$ at the regional scale}

Starting with the SDM obtained for Red-backed Shrike in Lombardy, each of the I-ha (average territory size of the species in Lombardy) cells of the regional area was reclassified as unsuitable, potentially suitable and suitable, according to the thresholds selected (maximum training sensitivity plus specificity threshold, equal to 0.185 , and equal training sensitivity and specificity threshold, 


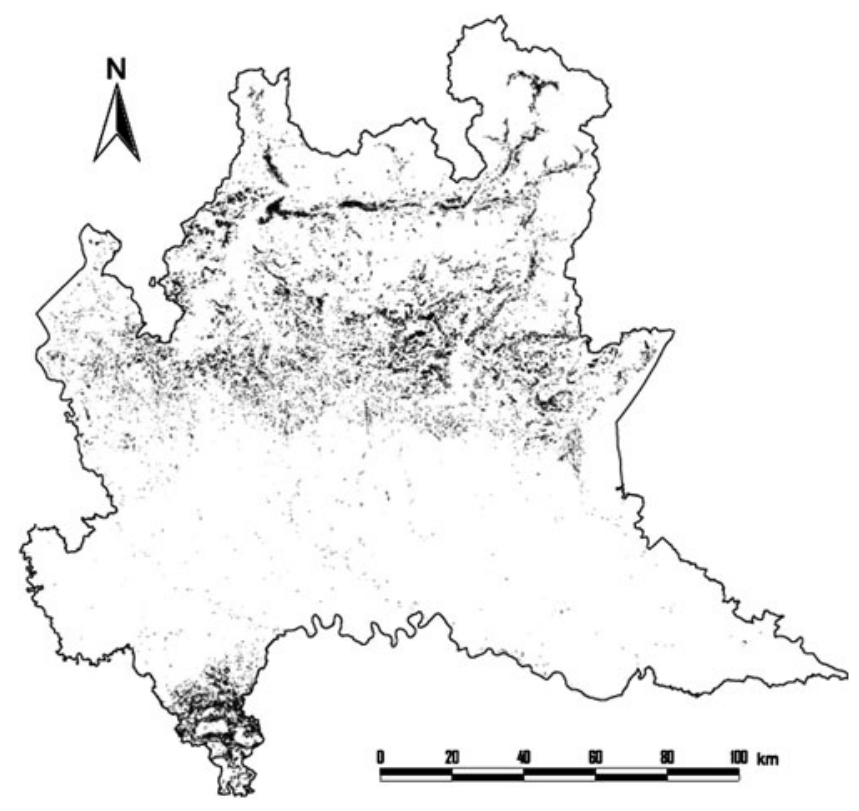

Figure 1. Species distribution model for Lanius collurio in Lombardy used for the definition of extent HRV. White - unsuitable area; pale grey - partly suitable area; dark grey - suitable area.

equal to 0.271 ). Cells with occurrence probability lower than 0.185 were classified as unsuitable, cells with occurrence probability between the two thresholds (0.185-0.271) as potentially suitable, and cells with occurrence probability above 0.271 were considered as suitable.

On the basis of the model output, 52,416 ha can be considered as potentially suitable and 111,501 ha as suitable. Overall, the study region includes 163,917 ha (corresponding to $c .7 \%$ of the regional area) potentially suitable for the species, on the basis of vegetation and landscape traits (land-cover, linear elements, elevation, slope, aspect, etc.). Such a value can be taken as extent HRV for the species in Lombardy.

\section{Quality HRV based on species distribution model}

We used the above SDM, built with fine-scaled habitat traits, to define quality HRV for the same species in the same region, Red-backed Shrike in Lombardy. For that species, a previous SDM (worked out for the same region with a slightly lower amount of occurrence data) could also estimate reproductive parameters (Brambilla and Ficetola 2012). According to a jackknife test of variable importance (and coherently with percentage contribution of variables), the most important factors for the species in Lombardy were permanent grassland, elevation, slope, broadleaved woodland and continuous hedgerows. Considering the species-habitat relationship curves, it is possible to propose as "favourable values", corresponding to high suitability (occurrence probability $>0.5$ ), the following: permanent grassland (percentage cover $>40 \%$ ), elevation $\left(<1,700 \mathrm{~m}\right.$ asl), slope $\left(<30^{\circ}\right)$, broadleaved woodland (absent or very scarce), shrubs (percentage cover $5-50 \%$ ) and continuous hedgerows (length $>25 \mathrm{~m}$ ). Those figures together (i.e. all conditions fulfilled) can be taken as a quality HRV for Red-backed Shrike in the study region, and the habitat they define closely resembles the habitat mosaic depicted as ideal for the species by a previous assessment of its ecological preferences, based on variables measured in the field (Brambilla et al. 2009, Casale and Brambilla 2009). 


\section{Discussion}

The use of reference values can contribute to the definition of the conservation status of a species or a population (Gustin et al. 2009, 2010). If the condition of a species (population) clearly deviates from the favourable reference terms proposed for it, that species cannot be considered to have a healthy status. Reference values have been recently proposed (and developed for some species/ parameters) as a tool for species conservation and they represent the minimum thresholds to be fulfilled for a bird species to be considered in favourable conservation status.

FRVs basically apply to three different levels: population (FRV-P), range (RRV) and habitat (HRV), and all the deriving conditions have to be fulfilled for a species/population to be in favourable status. Defining a method for setting HRV is a challenging task. The HRV concept is necessarily two-sided, as the status of the habitat of a species depends on both its spatial availability (extension) and characteristics, which can affect local occurrence, density, and reproduction (quality).

The use of models of habitat selection, which can be made spatially explicit, generating distribution models, may assist the definition of both extension and quality HRVs. Specieshabitat models are based on the definition of the relationships between a species and the environmental traits of the occupied habitat; they can allow the individuation of factors and relative values affecting species occurrence and reproduction (quality HRV), and the definition of the spatial distribution and quantity of potentially suitable habitat (extent HRV).

Our approach to extent HRVs is transferable to several other contexts, as it is based on 'standard' production of SDMs, but model accuracy depends on resolution and accuracy of the layer data available for modelling distribution. Most importantly, the use of SDMs or other species-habitat models based on occurrence and/or habitat selection for the definition of quality HRV, should be subjected to an evaluation of the coherence between habitat suitability and quality. In our study example, previous knowledge suggests that habitat suitability and quality are correlated (Brambilla and Ficetola 2012).

Extent HRV defined on the basis of SDMs should be large enough to support a population at its respective FRV or above (when defined as the number of pairs or individuals). Extent HRV can also be used to convert density-based population FRVs into population size. By applying favourable density values (proposed as FRV for abundant species; Brambilla et al. 2011) to the area defined as extent HRV, it should be possible to extrapolate a 'favourable' potential population at the same spatial scale used for distribution modelling, which could be taken as population FRV (based on population size, instead of density). Notably, habitat suitability estimated by SDMs may help calculate the upper limit of abundance (VanDerWal et al. 2009).

Our extent HRV is based on present availability of potentially suitable habitat. Although backcasting the past species' distribution and forecasting the future one (and hence past and future habitat availability) is sometimes feasible (see e.g. Acevedo et al. 2012), detailed habitat data for past and future scenarios are hardly ever available. Whenever possible, changes from past and future prospections of habitat availability can be taken into account. A recent (last 20-30 years) reduction in habitat availability should result in an extent HRV larger than the current extent of suitable habitat: ideally, HRV should be more ambitious, to compensate for recent habitat losses. Future scenarios or visions can be used to calibrate values according to supposed changes in the next decades. Extent HRV larger than the current extent of suitable habitat can be proposed for species for which the ongoing or predicted environmental changes are leading to an increase in suitable habitat.

The definition of quality HRV is somewhat complicated by availability of data encompassing both habitat selection and effect of habitat features on breeding performances (and potentially other reproductive and/or population parameters).

We believe it is important that environmental factors used for quality HRV definition are measured at a relevant spatial scale, which for several bird species should coincide with the scale of breeding territories. Such fine-scaled factors are also more likely to affect breeding success (Brambilla and Ficetola 2012) than large-scaled, coarse factors (e.g. bioclimatic data). The increasing availability of high-resolution habitat data will allow better assessment of ecologically relevant traits at fine spatial scales (Mendenhall et al. 2011, Brambilla and Ficetola 2012). 
In addition to the spatial scale, the geographical scale at which HRVs are proposed should also be carefully considered. In many species, regional differences in habitat preferences and factors affecting habitat quality can occur (see e.g. Whittingham et al. 2007), and thus it may be worth investigating the species' ecology and formulating the consequent reference values at regional or sub-national levels, to avoid encompassing too large a difference in species' responses to habitat factors.

Species performing within-season shifts in habitat/distribution pose a challenge for HRV definition (Brambilla et al. 2012a,b). For those species, a single value of quality HRV or two different quality HRVs have to be defined according to the degree of change in species-habitat relationships between the two broods, and the optimal solution for the same species may vary across areas and regions and according to area-specific potential patterns of temporal occurrence.

Obviously, ours is one possible approach, aiming at finding a "suitable" trade-off between affordable data and scientific precision, but several other solutions might be found, including e.g. fine-scaled studies of habitat selection (Brambilla et al. 2012a, Ceresa et al. 2012, Brambilla et al. 2013b). Territory size, importance of micro-habitat, data availability on breeding success, etc. might orient the choice between SDMs and habitat preference models for the definition of quality HRV (Brambilla et al. 2012a).

\section{Acknowledgements}

We are grateful to I. Negri, F. Reginato, S. Vitulano for help with fieldwork, and to the sub-group on conservation objectives of the task force of BirdLife International on the Habitat Directive, and in particular to B. Barov, A. Brunner, I. Burfield, R. Foppen, S. Herbert, K. Kreiser for helpful discussion and comments. The method presented in this work has contributed to the development of a position paper on conservation objectives by BirdLife International. This study was partially funded by the Italian Ministry of Environment, Direction Nature Protection and Sea.

\section{References}

Araújo, M. B. and Williams, P. H. (200o) Selecting areas for species persistence using occurrence data. Biol. Conserv. 96: 331-345.

Acevedo, P., Melo-Ferreira, J., Real, R. and Alves, P. C. (2012) Past, present and future distributions of an Iberian endemic, Lepus granatensis: Ecological and evolutionary clues from species distribution models. PLOS ONE 7: e51529.

Bionda, R. and Brambilla, M. (2012) Rainfall and landscape features affect productivity in an alpine population of Eagle Owl Bubo bubo. J. Ornithol. 153: 167-171.

Bourg, N. A., McShea, W. J. and Gill, D. E. (2005) Putting a CART before the search: successful habitat prediction for a rare forest herb. Ecology 86: 2793-2804.

Brambilla, M. and Ficetola, G. F. (2012) Species distribution models as a tool to estimate reproductive parameters: a case study with a passerine bird species. J. Anim. Ecol. 81: $781-787$.

Brambilla, M. and Pedrini, P. (2011) Intraseasonal changes in local pattern of Corncrake Crex crex occurrence require adaptive conservation strategies in Alpine meadows. Bird Conserv. Internatn. 21: 388-393.

Brambilla, M. and Rubolini, D. (2009) Intraseasonal changes in distribution and habitat associations of a multi-brooded bird species: Implications for conservation planning. Anim. Conserv. 12: 71-77.

Brambilla, M., Bassi, E., Bergero, V., Casale, F., Chemollo, M., Falco, R., Longoni, V., Saporetti, F., Viganò, E. and Vitulano, S. (2013a) Modelling distribution and potential overlap between Boreal Owl Aegolius funereus and Black Woodpecker Dryocopus martius: implications for management and monitoring plans. Bird Conserv. Internatn. doi: 10.1017/S0959270913000117.

Brambilla, M., Casale, F., Bergero, V., Crovetto, G. M., Falco, R., Negri, I., Siccardi, P. and Bogliani, G. (2009) GIS-models work well, but are not enough: Habitat preferences 
of Lanius collurio at multiple levels and conservation implications. Biol. Conserv. 142: 2033-2042.

Brambilla, M., Bassi, E., Ceci, C. and Rubolini, D. (2010a) Environmental factors affecting patterns of distribution and co-occurrence of two competing raptor species. Ibis 152: 310-322.

Brambilla, M., Casale, F., Bergero, V., Bogliani, G., Crovetto, G. M., Falco, R., Roati, M. and Negri, I. (2010b) Glorious past, uncertain present, bad future? Assessing effects of land-use changes on habitat suitability for a threatened farmland bird species. Biol. Conserv. 143: 2770-2778.

Brambilla, M., Celada, C. and Gustin, M. (2012a) Definizione dei Valori di Riferimento Favorevole per l'habitat e il range delle specie di uccelli. Roma: Ministero dell'Ambiente, della Tutela del Territorio e del Mare, LIPU/ BirdLife Italia.

Brambilla, M., Falco, R. and Negri, I. (2012b) A spatially explicit assessment of withinseason changes in environmental suitability for farmland birds along an altitudinal gradient. Anim. Conserv. 15: 638-647.

Brambilla, M., Fulco, E., Gustin, M. and Celada, C. (2013b) Habitat preferences of the threatened Black-eared Wheatear Oenanthe hispanica in southern Italy. Bird Study 6o: 432-435.

Brambilla, M., Gustin, M. and Celada, C. (2011) Defining Favourable Reference Value for bird populations in Italy: setting longterm conservation target for priority species. Bird Conserv. Internatn. 21: 107-118.

Casale, F. and Brambilla, M. (2009) Averla piccola. Ecologia e conservazione. Milano: Fondazione Lombardia per l'Ambiente \& Regione Lombardia.

Ceresa, F., Bogliani, G., Pedrini, P. and Brambilla, M. (2012) The importance of key marginal habitat features for birds in farmland: an assessment of habitat preferences of Red-backed Shrikes Lanius collurio in the Italian Alps. Bird Study 59: 327-334.

Elith, J., Graham, C. H., Anderson, R. P., Dudík, M., Ferrier, S., Guisan, A., Hijmans, R. J, Huettmann, F., Leathwick, J. R., Lehmann, A., Li, J., Lohmann, L. G., Loiselle, B. A., Manion, G., Moritz, C., Nakamura, M., Nakazawa, Y., Overton, J. M., Peterson, A. T., Phillips, S. J., Richardson, K. S., Scachetti-Pereira, R., Schapire, R. E., Soberon, J., Williams, S.,
Wisz, M. S. and Zimmermann, N. E. (2006) Novel methods improve prediction of species' distributions from occurrence data. Ecography 29: 129-151.

Elith, J., Phillips, S. J., Hastie, T., Dudík, M. Y., Chee, E. and Yates, C. J. (2011) A statistical explanation of MaxEnt for ecologists. Divers. Distrib. 17: 43-57.

European Commission (2005) Assessment, monitoring and reporting of conservation status - Preparing the 2001-2006 report under Article 17 of the Habitats Directive. Note to the Habitats Committee, 15 March 2005. Brussels: European Commission, Directorate-General Environment.

Ferrier, S., Watson, G., Pearce, J. and Drielsma, M. (2002) Extended statistical approaches to modelling spatial pattern in biodiversity in northeast New South Wales. I. Species-level modelling. Biodivers. Conserv. 11: 2275-2307.

Förschler, M. I., Borras, A., Cabrera, J., Cabrera, T. and Senar, C. J. (2005) Inter-locality variation in reproductive success of the citril finch Serinus citrinella. J. Ornithol. 146: 137-140.

Fouquet, A., Ficetola, G. F., Haigh, A. and Gemmell, N. (2010) Using ecological niche modelling to infer past, present and future environmental suitability for Leiopelma hochstetteri, an endangered New Zealand native frog. Biol. Conserv. 143: 1375-1384.

Gilroy, J. J., Anderson, G. Q. A., Grice, P. V., Vickery, J. A. and Sutherland, W. J. (2010) Mid-season shifts in the habitat associations of Yellow Wagtails Motacilla flava breeding in arable farmland. Ibis 152: 90-104.

Graham, C. H., Ferrier, S., Huettman, F., Moritz, C. and Peterson, A. T. (2004) New developments in museum-based informatics and applications in biodiversity analysis. Trends Ecol.Evol. 19: 497-503.

Gustin, M., Brambilla, M. and Celada, C. (2009) Valutazione dello stato di conservazione dell'avifauna italiana. Roma: Ministero dell'Ambiente, della Tutela del Territorio e del Mare \& LIPU/BirdLife Italia.

Gustin, M., Brambilla, M. and Celada, C. (2010) Stato di conservazione dell'avifauna italiana - le specie nidificanti e svernanti in Italia non inserite nell'Allegato I della Direttiva Uccelli. Roma: Ministero dell'Ambiente e della Tutela del Territorio e del Mare \& LIPU/BirdLife Italia. 
Hall, L. S., Krausman, P. R. and Morrison, M. L. (1997) The habitat concept and a plea for standard terminology. Wildl. Soc. Bull. 25: 173-182.

Jiménez-Valverde, A., Lobo, J. M. and Hortal, J. (2008) Not as good as they seem: the importance of concepts in species distribution modelling. Divers. Distrib. 14: 885-89o.

Kragten, S. (2011) Shift in crop preference during the breeding season by Yellow Wagtails Motacilla flava flava on arable farms in The Netherlands. J. Ornithol. 152: 751-757.

Mehtala, J. and Vuorisalo, T. (2007) Conservation policy and the EU Habitats Directive: favourable conservation status as a measure of conservation success. Environ. Policy and Governance 17: 363-415.

Mendenhall, C. D., Sekercioglu, C. H., Brenes, F. O., Ehrlich, P. R. and Daily, G. C. (2011) Predictive model for sustaining biodiversity in tropical countryside. Proc. Natl. Acad. Sci. U. S. A. 108: 16313-16316.

Ortego, J. (2007) Consequences of Eagle Owl nest-site habitat preference for breeding performance and territory stability. Ornis Fennica 84: 78-90.

Phillips, S. J., Anderson, R. P. and Schapire, R. E. (2006) Maximum entropy modeling of species geographic distributions. Ecol. Model. 190: 231-259.

Pihl, S., Clausen, P., Laursen, K., Madsen, J. and Bregnballe, T. (2006) Conservation status of bird species in Denmark covered by the EU Wild Birds Directive. Copenhagen:
Ministry of Environment, National Environmental Research Institute. (NERI Technical Report No. 570).

Raxworthy, C. J., Martinez-Meyer, E., Horning, N., Nussbaum, R. A., Schneider, G. E., Ortega-Huerta, M. A. and Peterson, A. T. (2003) Predicting distributions of known and unknown reptile species in Madagascar. Nature 426: 837-841.

Sergio, F., Marchesi, L. and Pedrini, P. (2004) Integrating individual habitat choices and regional distribution of a biodiversity indicator and top predator. J. Biogeogr. 31: 619-628.

Sergio, F., Pedrini, P. and Marchesi, L. (2003) Spatio-temporal shifts in gradients of habitat quality for an opportunistic avian predator. Ecography 26: 243-255.

Thuiller, W., Richardson, D. M., Pysêk, P., Midgley, G. F., Hughes, G. O. and Rouget, M. (2005) Niche-based modelling as a tool for predicting the risk of alien plant invasions at a global scale. Global Change Biol. 11: 2234-2250.

VanDerWal, J., Shoo, L. P., Johnson, C. N. and Williams, S. E. (2009) Abundance and the environmental niche: Environmental suitability estimated from niche models predicts the upper limit of local abundance. Am. Nat. 174: 282-291.

Whittingham, M. J., Krebs, J. R., Swetnam, R. D., Vickery, J. A., Wilson, J. D., and Freckleton, R. P. (2007) Should conservation strategies consider spatial generality? Farmland birds show regional not national patterns of habitat association. Ecol. Lett. 10: 25-35.

\section{MATTIA BRAMBILLA*}

Lega Italiana Protezione Uccelli (LIPU/BirdLife Italia), via Udine 3/a, I-43122, Parma, Italy; Fondazione Lombardia per l'Ambiente, Settore Biodiversità e Aree protette, Largo 1o luglio 1976 1, I-20822 Seveso (MB), Italy; Museo delle Scienze, Sezione di Zoologia dei Vertebrati, Via Calepina 14, I-38122 Trento, Italy.

\section{CLAUDIO CELADA, MARCO GUSTIN}

Lega Italiana Protezione Uccelli (LIPU/BirdLife Italia), via Udine 3/a, I-43122, Parma, Italy.

*Author for correspondence; e-mail: brambilla.mattia@gmail.com 